\title{
Physical and Electrochemical Characterization of Modified Graphite Nanoparticles-Phosphotungstic Acid-Nafion on Glassy Carbon Electrode for Bisphenol A Determination
}

\author{
Azrilawani Ahmad 1,*(D), Law Chia Huei ${ }^{1}$ (D) \\ 1 Faculty of Science and Marine Environment, Universiti Malaysia Terengganu, 21030 Kuala Nerus, Terengganu, Malaysia \\ * Correspondence: azrilawani.ahmad@umt.edu.my;
}

Scopus Author ID 57192659046

Received: 6.08.2020; Revised: 4.09.2020; Accepted: 7.09.2020; Published: 10.09.2020

\begin{abstract}
A simple and rapid electrochemical sensor based on modified graphite nanoparticle with phosphotungstic acid and Nafion (GN-PTA-nafion) on glassy carbon electrode (GCE) has been developed for detecting bisphenol A (BPA). The GN was characterized using a scanning electron microscope (SEM) and X-ray diffractometer (XRD), while the modified GCE was characterized using differential pulse voltammetry (DPV) and cyclic voltammetry (CV). Several parameters such as GN concentration, scan rate, equilibrium time, and $\mathrm{pH}$ of phosphate buffer were optimized in this study. The GN-PTA-Nafion modified GCE that consists of graphite nanoparticle with a large surface area showed better and faster electron transfer, whereas the phosphotungstic acid (PTA) increased the sensitivity of the electrode for BPA detection. Good electrochemical performances for analyzing BPA, with a detection limit of $0.3995 \mathrm{~mol} \mathrm{~L}^{-1}$, as well as good reproducibility (RSD $2.51 \%$ ) were obtained. The modified electrode showed that it had short analysis time, inexpensive and good sensitivity for BPA detection.
\end{abstract}

Keywords: graphite nanoparticle; phosphotungstic acid; Nafion; bisphenol A.

(C) 2020 by the authors. This article is an open-access article distributed under the terms and conditions of the Creative Commons Attribution (CC BY) license (https://creativecommons.org/licenses/by/4.0/).

\section{Introduction}

Bisphenol A (BPA) is a chemical that is widely used as an additive in industrial for the manufacturing of epoxy resins (EP) and polycarbonate (PC) plastics. It is mostly found in plastics drinking water, cans, and coating of metal food containers [1]. BPA may leach under certain conditions of heat, as well as basic and acidic conditions, which later may result in exposure to humans [2]. There are also the chances of its migration or leaching into the drinking water from its container or bottle that are made from material such as epoxy resins and polycarbonate plastics [3]. BPA is known as an endocrine disruptor that has adverse effects on humans in previous studies [4]. The overdose intake of BPA may lead to severe weight loss and leukemia, whereas the low doses intake of BPA may weaken the endocrine system, which affects the behavior, metabolism, or human development [5].

Numerous studies have been focused on the development of methods and sensing system for the determination of BPA in various matrices. These include techniques such as chromatography [6-9], biosensor [10-12], as well as electrochemical sensors [13-15]. Chromatographic methods are proven to have the capability for quantitative determination at a 
lower limit of detection [16-17]. However, pre-treatment of samples is often needed, as well as costly due to the laboratory-bound instrumentation.

For the past decades, the electrochemical method has proven to be a good alternative to compliment chromatographic techniques in various applications such as environmental monitoring [18-19], clinical diagnostic [20], as well as in food analysis [14]. There are many electrochemical methods or sensors that were used for the detection of BPA using direct oxidation reaction due to their short analysis time, inexpensive, and great sensitivity [21-22]. BPA was detected using an oxidation reaction with an electrochemically active electrode material such as carbon or graphene [23]. The oxidation took place at the working electrode. The oxidation of BPA may increase the interferences that contribute to the lower sensitivity and selectivity [24]. These effects of oxidation are overcome by the modification of the electrode. Besides, modification of electrode can also improve the rate of electron transfer and the adsorption of an analyte, which later contributed to a greater limit of detection [25]. There are many different nanomaterials that are proven to improve the sensitivity of the sensor due to their excellent carrier properties [26].

Graphite nanoparticle (GN) is a number of graphene sheets that are stacked together. It is high conductivity and large surface area. The nanomaterial is used to fabricate the sensor due to the BPA that shown a slow electron transfer with the use of a bare electrode [27]. GN electrode was produced by GN with its large surface area that provides a faster electron transfer with greater BPA build-up, and this shown good adsorption property and give a better analysis of BPA. A high selectivity, stability, and reproducibility for BPA are shown by GN. GN electrode showed a greater conductivity and sensitivity compared with bare GCE [28].

In this study, graphite nanoparticle modified phosphotungstic acid and Nafion (GNPTA-Nafion) were prepared and cast on GCE for BPA detection. PTA was used as it can significantly improve the reproducibility and repeatability of the electrode [23], while Nafion was used as it has high chemical stability and ability to resist interferences [29]. GN-PTANafion modified GCE as a working electrode, silver/silver chloride ( $\mathrm{Ag} / \mathrm{AgCl})$ as a reference electrode, and platinum $(\mathrm{Pt})$ wire as a counter electrode were used for further electrochemical measurement. The modified GCE surface was then be observed with oxidation peaks in the differential pulse voltammetry (DPV) for its selectivity and sensitivity towards BPA. This developed method provides short analysis time, inexpensive and good sensitivity.

\section{Materials and Methods}

\subsection{Chemicals and materials.}

Bisphenol A (BPA) (97\%), Nafion solution (5 wt \% in a mixture of lower aliphatic alcohols and water), and phosphate buffer were purchased from Sigma-Aldrich, USA. Graphite powder and potassium ferricyanide were obtained from $\mathrm{R} \& \mathrm{M}$ Chemicals, the United Kingdom, and phosphotungstic acid (PTA) powder was obtained from EMD Millipore, USA. Anhydrous methanol and potassium chloride were from Merck KGaA, Germany, and alumina slurry for polishing glassy carbon electrode (Sigma-Aldrich, USA) was used in this research. All reagents were of analytical grade or better.

\subsection{Preparation of graphite nanoparticles.}

The graphite powder was milled using a planetary ball mill (model PM 100, Retsch Laboratory Mills, Germany) at the rotation speed of $200 \mathrm{rpm}, 250 \mathrm{rpm}$, and $300 \mathrm{rpm}$ for 3 hours 
each and $200 \mathrm{rpm}$ for a period of 5 hours and 6 hours. The $50 \mathrm{~mL}$ capacity stainless steel grinding jar with 5 stainless steel balls of $8 \mathrm{~mm}$ diameter was used as the grinding medium.

\subsection{Characterization of graphite nanoparticles.}

The characterization of milled graphite powder was carried out using a scanning electron microscope (SEM) (model JSM-6610LV, JEOL, USA) and X-ray diffractometer (XRD) (model Rigaku Miniflex II, Rigaku, Japan). The parameter of SEM used for characterization was $10 \mathrm{kV}$ at the magnification of $\times 20,000$ to obtain the average particle size. XRD for milled graphite analysis used the start angle of $10^{\circ}$ and stopped angle of $80^{\circ}$ with an $\mathrm{X}$-ray output of $30 \mathrm{kV}, 15 \mathrm{~mA}$, and the scan speed of $2^{\circ}$ per minutes.

\subsection{GN-PTA-nafion electrode modification.}

The glassy carbon electrode (GCE) was polished using alumina slurry. The polished GCE was then washed with distilled water to obtain a clean surface. The GCE was later dried at the room temperature. $12 \mathrm{mg}$ of graphite nanoparticles $(\mathrm{GN})$ were prepared with $5 \mathrm{~mL}$ distilled water and sonicated for 5 minutes that later produced a $0.20 \mathrm{~mol} \mathrm{~L}^{-1} \mathrm{GN}$ solution, while $144 \mathrm{mg}$ of phosphotungstic acid (PTA) was added to $1 \mathrm{~mL}$ of distilled water to produce a $0.05 \mathrm{~mol} \mathrm{~L}^{-1}$ of PTA solution. $1 \mu \mathrm{L}$ of GN was then dropped on the surface of GCE followed by $1 \mu \mathrm{L}$ PTA and dried at the room temperature, which is later deposited on the surface of GCE. $1 \mu \mathrm{L}$ Nafion then added on GN on the surface of GCE and resulting GN-PTA-Nafion film. The prepared GN-PTA-Nafion electrode was used as the working electrode. The simplified preparation of GN-PTA-Nafion is shown in Figure 1.

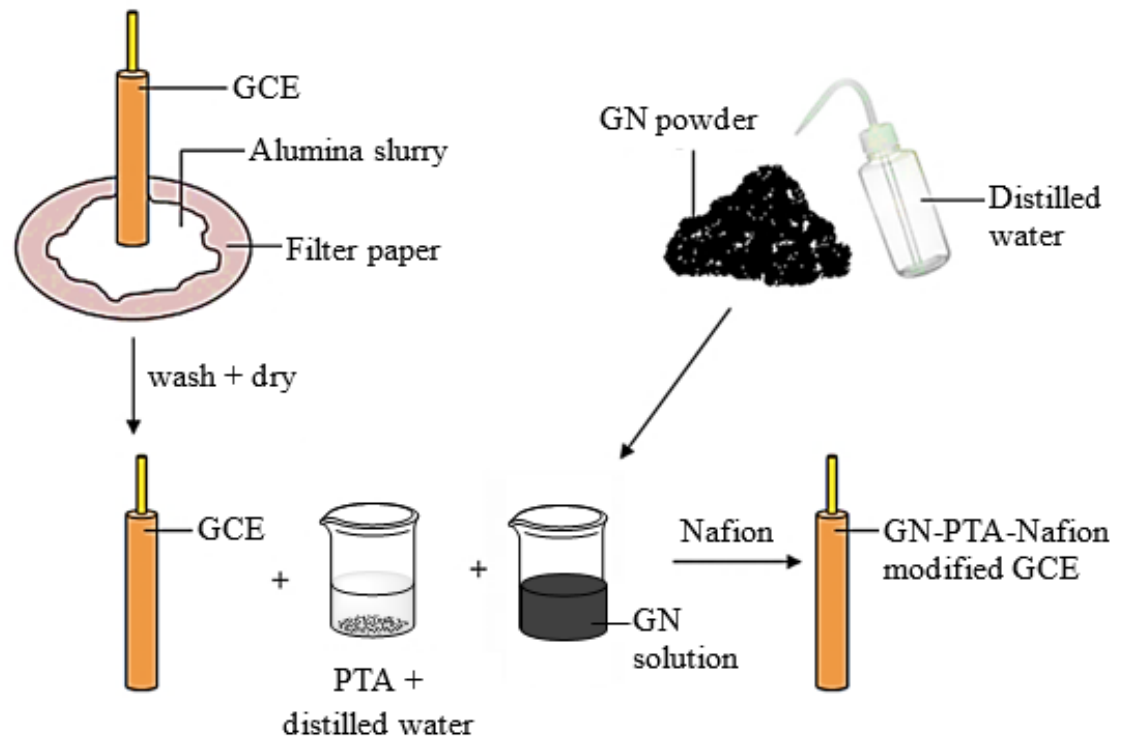

Figure 1. Preparation of GN-PTA-Nafion.

\subsection{Optimization of parameters.}

The parameters for an electrochemical method such as scan rate, $\mathrm{pH}$ of supporting electrolyte, equilibrium time, and the amount of GN loaded were obtained to ensure the most suitable condition for the electrochemical analysis or determination of BPA content and increases the reliability or quality of the results obtained.

The effect of the scan rate to the electrochemical behavior of BPA was investigated. Scan rate ranging from $10 \mathrm{mV} \mathrm{s}^{-1}$ to $200 \mathrm{mV} \mathrm{s}^{-1}$ at $\mathrm{pH} 7$ of supporting electrolyte was compared 
for the cyclic voltammetry (CV) response (PGSTAT 910, Metrohm). The electrochemical behaviors of an analyte, which is reduced or oxidized, were characterized using $\mathrm{CV}$. The anodic peak potential $\left(\mathrm{E}_{\mathrm{pa}}\right)$, cathodic peak potential $\left(\mathrm{E}_{\mathrm{pc}}\right)$, anodic peak current $\left(\mathrm{I}_{\mathrm{pa}}\right)$, and cathodic peak current $\left(\mathrm{I}_{\mathrm{pc}}\right)$ were observed and studied in the $\mathrm{CV}$.

The $\mathrm{pH}$ may affect the stability of the analyte and substances used to modify the electrode. Phosphate buffer was used as the supporting electrolyte for this research. The determination for the known BPA content in phosphate buffer with $\mathrm{pH}$ ranged from 4 to 10 using a modified electrode, and DPV was used to analyze the effects of $\mathrm{pH}$.

Equilibrium time will be able to improve the sensitivity of the sensor [3]. Six equilibrium time ranging from 5 seconds to 30 seconds were selected. Each equilibrium time for the detection of BPA was tested with DPV using BPA standard solution with known concentration. The adsorption that reached the saturation and was used as the processing equilibrium time for DPV.

The amount of GN loaded will contribute to better sensing of the current signal with the exception that it is too thick that end up resulting adsorbed molecules unable to transfer the electrons with its far distance [28]. However, if it is too thin, the reactive group will be fewer and lead to a weaker electrochemical response [30]. The most suitable amount of GN ranging from $6 \mathrm{mg}$ to $24 \mathrm{mg}$, which were $0.1 \mathrm{~mol} \mathrm{~L}^{-1}$ to $0.4 \mathrm{~mol} \mathrm{~L}^{-1}$ of GN solution, was loaded in the modified electrode preparation and was tested with a known concentration of BPA standard to ensure a better electrochemical sensing property.

\subsection{Measurement of the modified electrode using the electrochemical method.}

Three electrode systems with GN-PTA-Nafion electrode as working electrode, platinum (Pt) wire as the reference electrode, and silver/silver chloride ( $\mathrm{Ag} / \mathrm{AgCl})$ electrode as the auxiliary or counter electrode was used. The GN-PTA-Nafion electrode was incubated in BPA solution to ensure a better BPA enrichment and accumulation. It was analyzed using CV and differential pulse voltammetry (DPV) (PGSTAT 910, Metrohm). The process was repeated using bare GCE instead of GN-PTA-Nafion electrode for the comparison of their efficiency and performance. The $\mathrm{CV}$ was used to detect electrochemical properties of the modified electrode using $50 \mathrm{mM}$ potassium ferricyanide, $\mathrm{K}_{3}\left[\mathrm{Fe}(\mathrm{CN})_{6}\right]$ solution in $0.1 \mathrm{M} \mathrm{KCl}$. LOD and LOQ were identified by preparing a few standard solutions of BPA with different concentrations and were detected using the modified electrode.

\subsection{Reproducibility.}

The reproducibility of the modified electrode was identified by comparing the peak current of the fixed concentration of BPA $(0.05 \mathrm{M})$ using a newly modified electrode for each measurement.

\section{Results and Discussion}

\subsection{Physical characterization of milled graphite powder.}

The scanning electron microscope (SEM) was used for surface analysis, which provides the form or morphology for the surface. Figure 2 shows the surface morphology and the estimated particle size of milled graphite powder using SEM. 

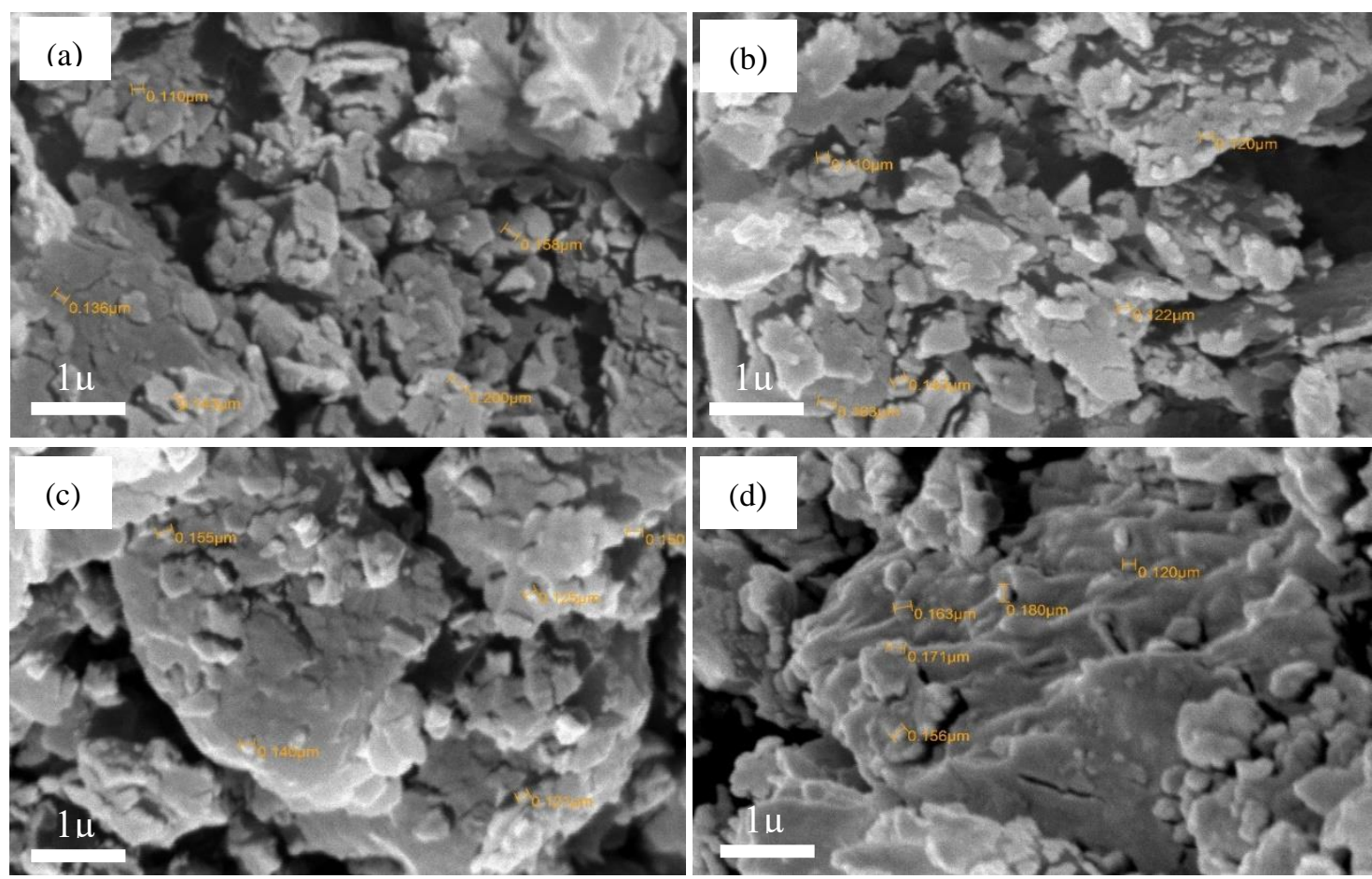

Figure 2. SEM of milled graphite powder for (a) 3 hours $250 \mathrm{rpm}$, (b) 3 hours $300 \mathrm{rpm}$, (c) 5 hours $200 \mathrm{rpm}$, and (d) 6 hours $200 \mathrm{rpm}$.

The milled graphite powder with different parameters was characterized using SEM with the magnification of $\times 20,000$ and $10 \mathrm{kV}$. The graphite powder was milled with a parameter of 3 hours for the speed of $250 \mathrm{rpm}$ and $300 \mathrm{rpm}, 5$ hours for speed of 200, and 6 hours with $200 \mathrm{rpm}$ using the planetary ball mill. The surface morphology showed that the graphite particles still maintain their crystallinity even after prolong milling, where graphite with its layered or flake structure [31]. The average estimated size of milled graphite powder was identified and calculated using 5 randomly chosen size. The resulting average size of graphite powder milled for 3 hours and $250 \mathrm{rpm}, 3$ hours and $300 \mathrm{rpm}, 5$ hours $200 \mathrm{rpm}$, and 6 hours $200 \mathrm{rpm}$ contained were $149.4 \mathrm{~nm}, 131.6 \mathrm{~nm}, 138.2 \mathrm{~nm}$, and $158.0 \mathrm{~nm}$, respectively. The reduction in particle size means that the milling method was effective as a fragmentation process for the graphite. Table 1 shows the centripetal force and kinetic force transferred during the milling process with the 6 stainless steel milling balls of $8 \mathrm{~mm}$ diameter.

The graphite powder was milled by moving in a circular path or movement in the milling bowl against the inner wall with the centrifugal force. When the stainless steel balls in the milling bowl compressed the graphite particles between them, the transfer of kinetic energy from milling ball to graphite particles occurred [32]. The centripetal force and transferred kinetic force was calculated using the following equations. (Equation 1 and Equation 2).

$$
\mathrm{F}=\mathrm{mr}^{2} \quad \text { (Equation 1) }
$$

where $\mathrm{F}$ is the centripetal or working force $(\mathrm{N})$ on the particles surface, $\mathrm{m}$ is mass of ball $(\mathrm{kg})$, $\mathrm{r}$ is the orbit radius $(\mathrm{m})$ of ball movement, and $\omega$ is angular speed or milling rate $\left(\mathrm{rad} \mathrm{s}^{-1}\right)$.

$$
\mathrm{E}=\frac{1}{2} \mathrm{nmv}^{2}
$$

(Equation 2)

where $\mathrm{E}$ is kinetic energy $(\mathrm{J}), \mathrm{n}$ is the number of balls, $\mathrm{m}$ is mass $(\mathrm{kg})$ of the ball, and $\mathrm{v}$ is tangential speed or circumferential velocity $\left(\mathrm{m} \mathrm{s}^{-1}\right)$. 
Table 1. Centripetal force and kinetic force are transferred in the milling process.

\begin{tabular}{c|c|c|c} 
Milling speed (rpm) & Milling rate $\left(\mathbf{r a d ~ s}^{-1}\right)$ & Centripetal force $(\mathbf{N})$ & Kinetic energy transferred $(\mathbf{J})$ \\
\hline 200 & 20.944 & 0.028 & $2.229 \times 10^{-3}$ \\
\hline 250 & 26.180 & 0.043 & $3.483 \times 10^{-3}$ \\
\hline 300 & 31.416 & 0.062 & $5.015 \times 10^{-3}$
\end{tabular}

X-ray diffractometer (XRD) was used to identify the particle size of the milled graphite powder. The analysis of particle size using XRD was fixed at the X-ray output of $30 \mathrm{kV}, 15$ $\mathrm{mA}$, and scan speed of $2^{\circ}$ per minute in the angle range of $10^{\circ}$ to $80^{\circ}$. Figure $3 \mathrm{a}$ and Figure $3 \mathrm{~b}$ show the X-ray diffraction graph for comparison of the milled graphite powder using the different parameters of speed and time for planetary ball mill, while Figure 4 shows the range where graphite peak appeared.
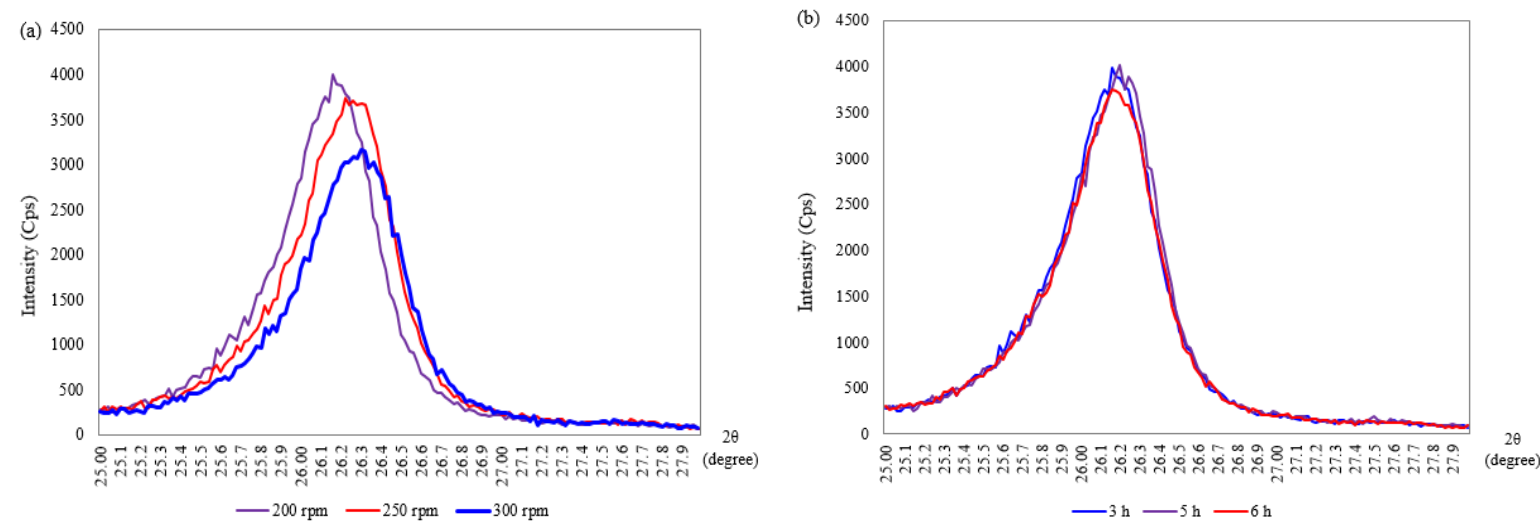

Figure 3. X-ray diffractometry of milled graphite powder with (a) different speed and (b) different milling period.

The range of maximum peak for graphite is at about $26^{\circ}$ [33-34], where the maximum peak obtained in this study is in the range of $26.134^{\circ}$ until $26.317^{\circ}$, which indicates that it has the structure of graphite and used for the calculation of particle size. Scherrer equation (Equation 3) was used to determine the particle size of graphite, where it is based on the peak broadening.

$$
\mathrm{D}=\frac{\mathrm{K} \lambda}{\beta \cos \theta} \quad \text { (Equation 3) }
$$

where $\mathrm{D}$ is crystallite or particle size $(\mathrm{nm}), \mathrm{K}$ is Scherrer constant $(0.9), \lambda$ is the wavelength of $\mathrm{X}$-rays radiation $(1.541 \AA$ or $0.154 \mathrm{~nm}), \beta$ is full width at the half maximum peak (FWHM) (radians), and $\theta$ is the diffraction angle or peak position (radians) [35].

The particle size was calculated using the full width at half maximum (FWHM) at the highest peak, and standard errors were identified. The XRD pattern of milled graphite powder using different milling time and speed was analyzed, as shown in Table 2.

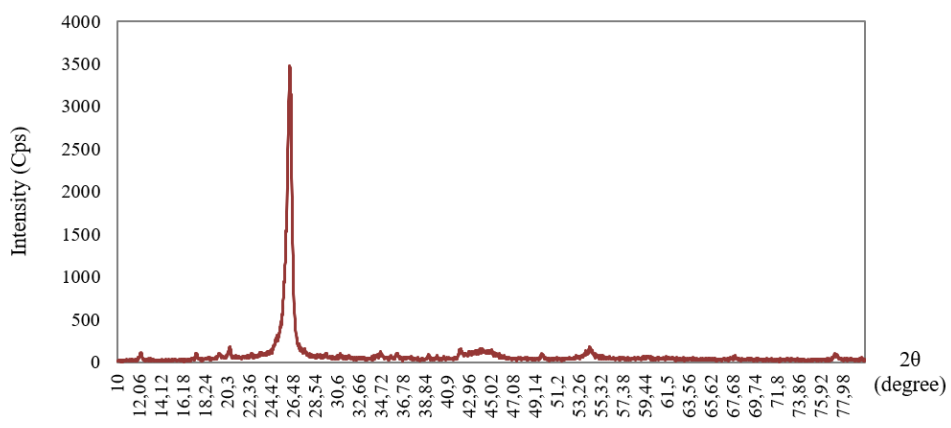

Figure 4. X-ray diffractometry of milled graphite powder with $300 \mathrm{rpm}$ for 5 hours. 
The size of graphite powder milled for 10 hours showed that the smallest particle obtained when compared to other milling time at the fixed milling speed parameter of $200 \mathrm{rpm}$. Whereas, the milling speed of $300 \mathrm{rpm}$ was obtained for the smallest in size by comparing at the fixed milling time of 3 hours. The reduced particle size will increase the surface area of the active site, thus increase its effectiveness [36].

Table 2. The particle size of graphite with different milling times and speed.

\begin{tabular}{c|c|c|c|c|c}
$\begin{array}{c}\text { Milling time } \\
\text { (hours) }\end{array}$ & $\begin{array}{c}\text { Milling speed } \\
(\mathrm{rpm})\end{array}$ & $2 \theta\left(^{\circ}\right)$ & FWHM & $\begin{array}{c}\text { Standard } \\
\text { error }\end{array}$ & $\begin{array}{c}\text { Particle } \\
\text { size }(\mathrm{nm})\end{array}$ \\
\hline 3 & 200 & 26.134 & 0.630 & 0.0033 & 12.937 \\
\hline 3 & 250 & 26.210 & 0.644 & 0.0030 & 12.661 \\
\hline 3 & 300 & 26.248 & 0.669 & 0.0031 & 12.188 \\
\hline 5 & 200 & 26.157 & 0.624 & 0.0029 & 13.062 \\
\hline 5 & 300 & 26.137 & 0.632 & 0.0033 & 12.914 \\
\hline 6 & 200 & 26.140 & 0.634 & 0.0029 & 12.860 \\
\hline 8 & 200 & 26.151 & 0.641 & 0.0031 & 12.716 \\
\hline 8 & 250 & 26.203 & 0.671 & 0.0033 & 12.159 \\
\hline 10 & 200 & 26.317 & 0.681 & 0.0033 & 11.985 \\
\hline 10 & 250 & 26.259 & 0.694 & 0.0035 & 11.760
\end{tabular}

\subsection{Modification of electrodes.}

The GCE was modified with different chemicals and analyzed using cyclic voltammetry with the fixed-parameter as following; scan rate of $100 \mathrm{mV} \mathrm{s}^{-1}$, start potential, and lower vertex potential of $-0.2 \mathrm{~V}$, upper vertex potential of $0.6 \mathrm{~V}$, stop the potential of -0.15 $\mathrm{V}$, and 11 number of scans. The GN-PTA-Nafion modified electrode showed a greater sensitivity compared to the bare GCE, GN, and PTA modified electrode (Figure 5). Based on this result, it is proven that GN has the capability to increase the electron transfer, thus improving the detection, while PTA contributed to the improvement of sensitivity.

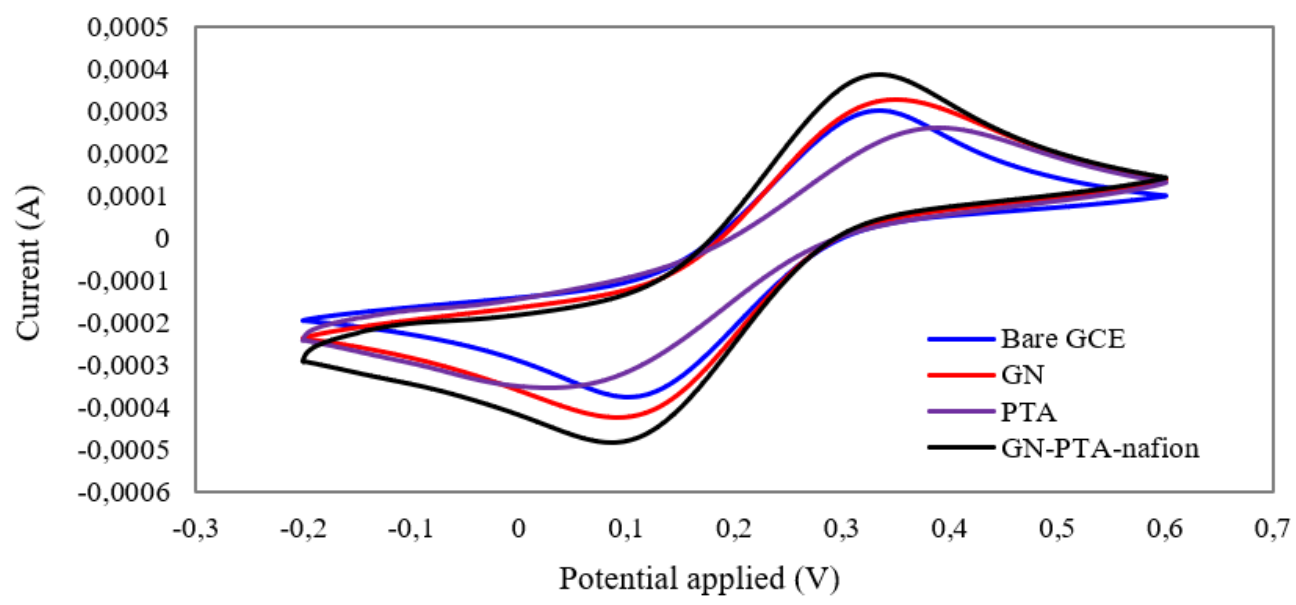

Figure 5. Cyclic voltammogram of comparison of modified electrode.

\subsection{Effect of scan rate, $p H$, equilibrium time, and amount of GN loaded.}

The optimization of GN concentration used for the modification of the electrode was carried out to ensure that the most suitable concentration was used. For the measurement of different $\mathrm{GN}$ concentrations ranging from $0 \mathrm{~mol} \mathrm{~L}^{-1}$ to $0.4 \mathrm{~mol} \mathrm{~L}^{-1}$, GN concentration at 0.2 mol L $\mathrm{L}^{-1}$ showed the greatest current signal, as shown in Figure 6. The peak current obtained slightly increased at $0.15 \mathrm{~mol} \mathrm{~L}^{-1}$ and reached the maximum peak at $0.2 \mathrm{~mol} \mathrm{~L}^{-1}$, where it later started to decrease until $0.4 \mathrm{~mol} \mathrm{~L}^{-1}$. The changes in peak current had proved that the GN concentration loaded to the GCE for modification contributed to the elevation effect of the 
current signal. The concentration of GN used will contribute to better sensing of current signal with the exception that it is too thick that end up resulting adsorbed molecules unable to transfer the electrons with its far distance [27]. However, the reactive group will be fewer and lead to a weaker electrochemical response if it is too thin [30]. Thus, $0.2 \mathrm{~mol} \mathrm{~L}^{-1}$ of GN is proven to be the most suitable for modification as it did not apply a too thick or too thin layer and allowed better sensing of current.

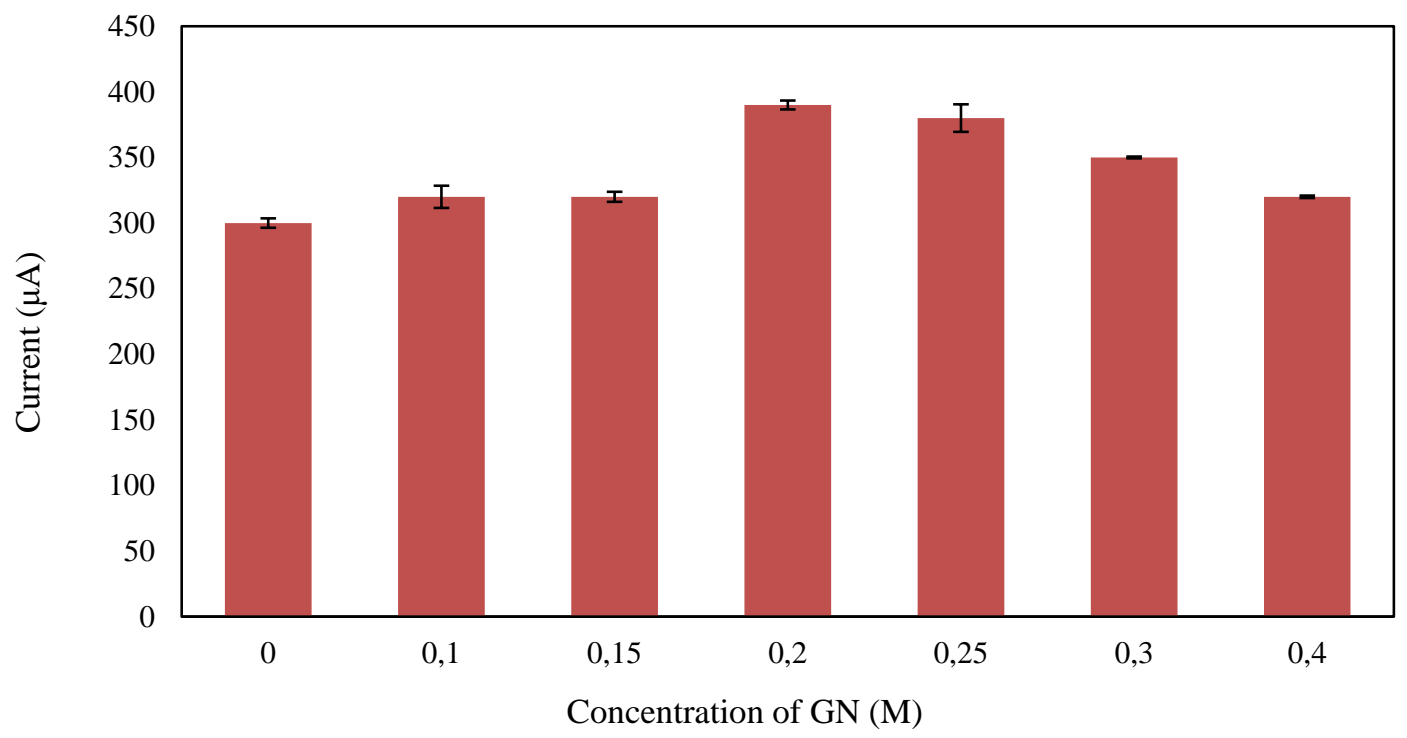

Figure 6. Graph of current against GN concentration
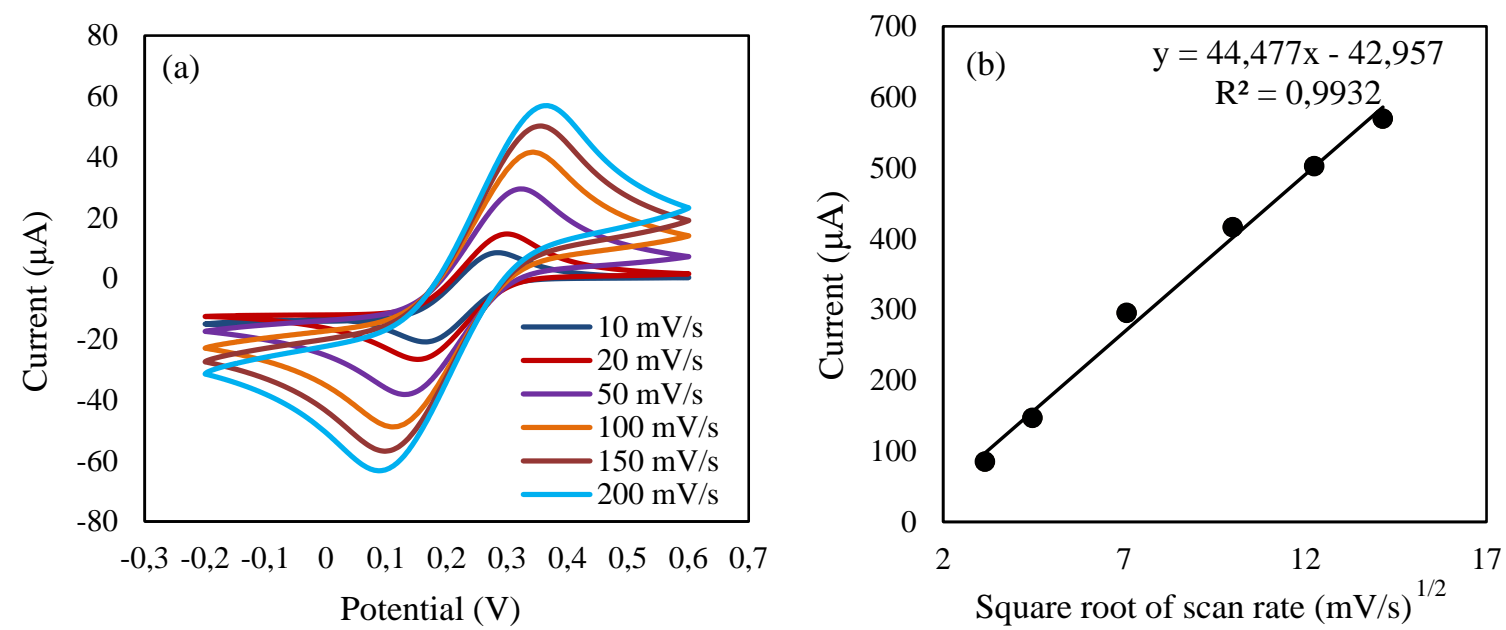

Figure 7. (a) Effect of scan rate on the CV response of GN-PTA-nafion on GCE with $5 \mathrm{mM} \mathrm{K}_{3}\left[\mathrm{Fe}(\mathrm{CN})_{6}\right]$ solution in $0.1 \mathrm{M} \mathrm{KCl}$; and (b) a plot of anodic peak current $\left(\mathrm{I}_{\mathrm{pa}}\right)$ versus square root of scan rate $\left(\mathrm{v}^{1 / 2}\right)$.

The effect of the scan rate was investigated, as shown in Figure $7 \mathrm{a}$. The $\mathrm{E}_{\mathrm{pa}}$ increased as the scan rate increased, which led to the distortion or broadening of peaks where the high polarization can be seen [37]. The increased voltage difference between the anodic peak and cathodic peak at a greater scan rate is proven. Even though the low scan rate had a greater detection, the scan rate of $100 \mathrm{mV} \mathrm{s}^{-1}$ was chosen for further measurement as it is a more practical application that had the sensitivity but not time-consuming. A plot of $\mathrm{I}_{\mathrm{pa}}$ versus square root of scan rate $\left(v^{1 / 2}\right)$ (Figure $7 b$ ) was obtained, with a good linear line with a $R^{2}$ of 0.9932 .

The optimized equilibrium time will be able to improve the sensitivity for the detection at a lower concentration. In this study, the optimization of equilibrium time was conducted in the range of 0 to 30 seconds at a scan rate of $100 \mathrm{mV} \mathrm{s}^{-1}$. The equilibrium time of 5 seconds showed the most optimized time, as the peak increased greatly compared to 0 seconds (Figure 
8). The peak current was increased from 0 seconds to the equilibrium time of 5 seconds and then decreased at 10 seconds and remained stable after that until 30 seconds of equilibrium time. This showed that the equilibrium time did not have much effect on the peak current after 5 seconds as a limited value of BPA amount on the surface of the electrode was achieved under the given situation [38].

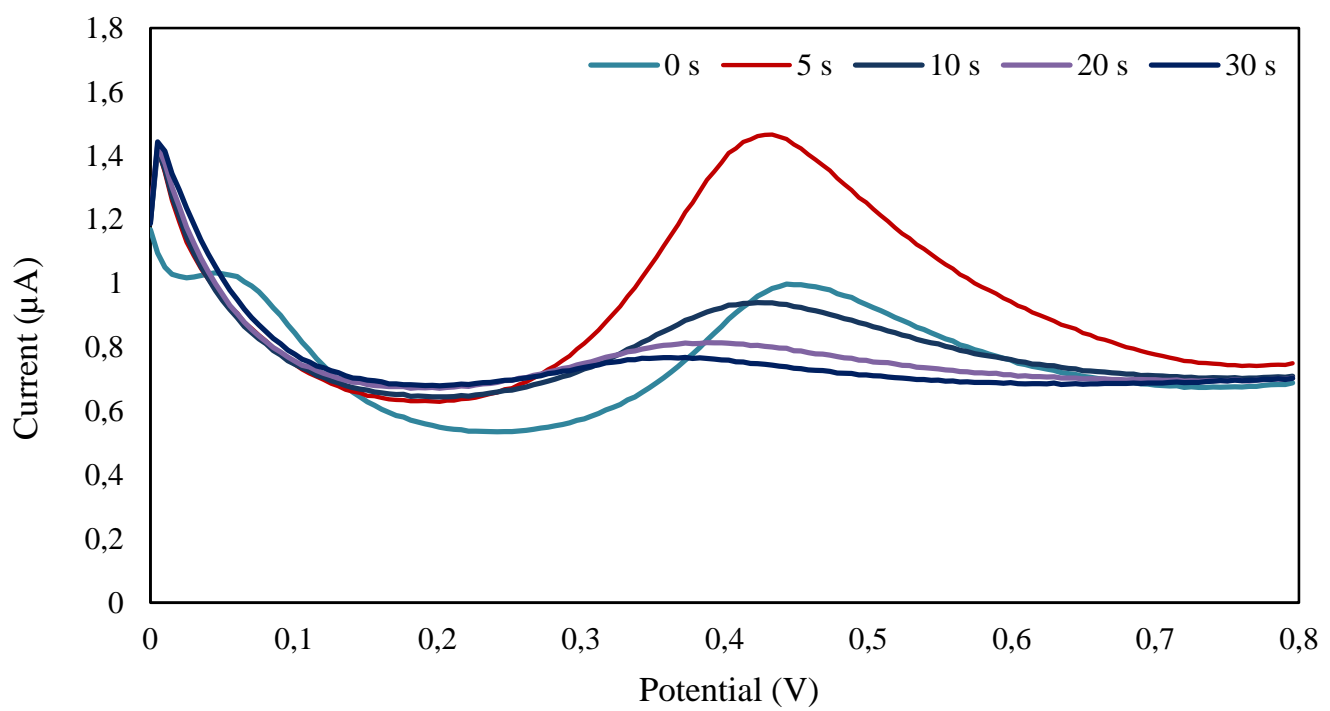

Figure 8. Graph of current against equilibrium time.

Differential pulse voltammetry (DPV) was used for the detection of BPA due to its effectiveness and high sensitivity that able to detect the content of the analyte even if it is very low. Thus several selected parameters were optimized. The optimization of $\mathrm{pH}$ for phosphate buffer solution as supporting electrolyte was carried out with the start potential of $0 \mathrm{~V}$ to stop the potential of $0.8 \mathrm{~V}$, equilibrium time of $5 \mathrm{~s}$, the step of $0.005 \mathrm{~V}$, modulation amplitude and time of $0.025 \mathrm{~V}$ and $0.05 \mathrm{~s}$ respectively and the interval time of $0.5 \mathrm{~s}$, with $\mathrm{pH}$ ranging from $\mathrm{pH} 4$ to $\mathrm{pH}$ 10. Figure 9 shows the peaks of $\mathrm{pH} 4$ and $\mathrm{pH} 6$ were not too observable, compared to the peaks at $\mathrm{pH} 8$ and $\mathrm{pH} 10$. This represents that the $\mathrm{pH}$ of phosphate buffer used influenced the peak current, indicating that the detection of BPA is more suitable in alkaline conditions. The current or detection of BPA was remarkably enhanced under the condition of $\mathrm{pH} 8$ for the phosphate buffer solution; thus, it is selected as the most optimized $\mathrm{pH}$ of buffer for further detection using DPV.

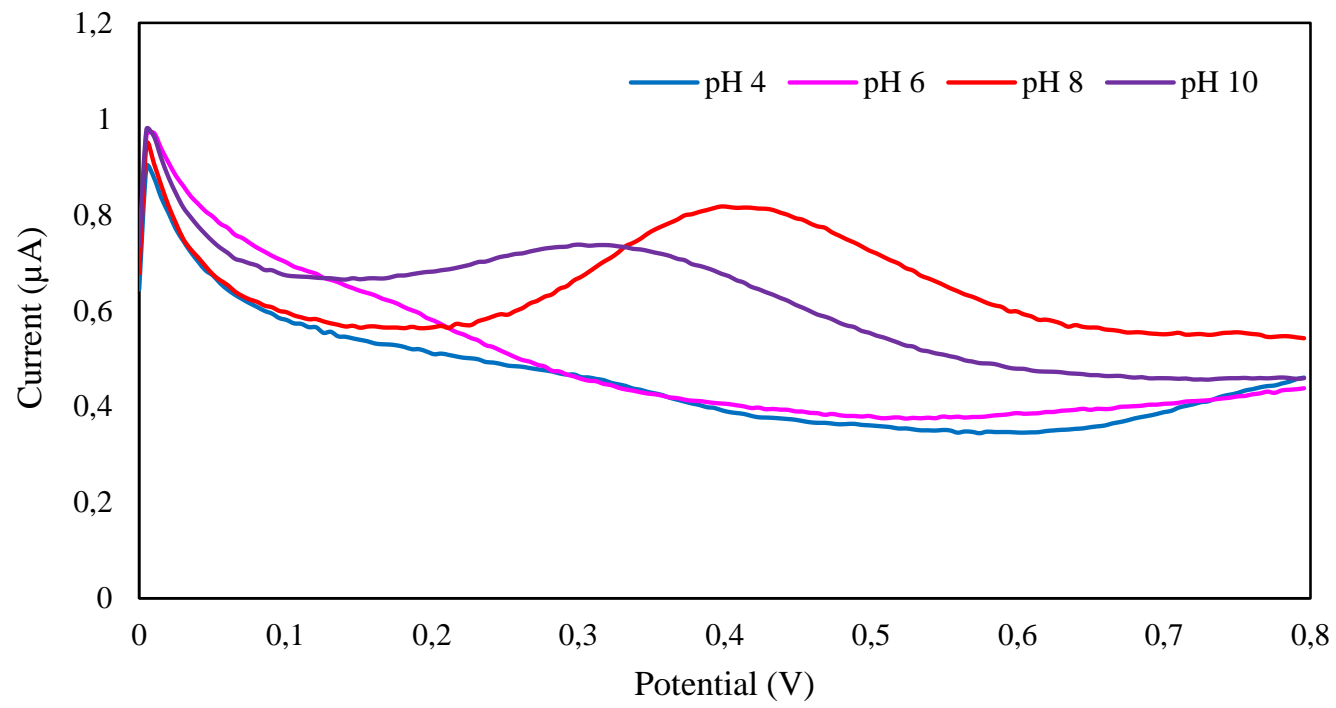

Figure 9. Differential pulse voltammogram for the effect of $\mathrm{pH}$. 


\subsection{Reproducibility studies of the modified electrode.}

The reproducibility of the modified electrode was identified by comparing the peak current of the fixed concentration of BPA $(0.05 \mathrm{M})$. The fixed BPA content was detected using a newly individual modified electrode. The RSD calculated was $2.51 \%$, where it indicates that the modified electrode had a great reproducibility.

3.5. $L O D, L O Q$, and percentage recovery from the calibration curve.

The limit of detection (LOD) and limit of quantification (LOQ) were calculated using (Equation 4), as shown below.

$$
\mathrm{LOD}=\frac{3 \sigma}{\mathrm{S}} \quad ; \quad \mathrm{LOQ}=\frac{10 \sigma}{\mathrm{S}} \quad \text { (Equation 4) }
$$

Where $\sigma$ is the standard deviation of peak current and $\mathrm{S}$ is the slope of the calibration curve. The calculated LOD is $0.3995 \mathrm{~mol} \mathrm{~L}^{-1}$, and LOQ is $1.332 \mathrm{~mol} \mathrm{~L}^{-1}$ with the standard deviation of $2.66 \times 10^{-7}$, as shown in Table 3 .

Table 3. Calculated aspects of the calibration curve.

\begin{tabular}{c|c|c|c|c} 
Slope & Intercept & Correlation coefficient & Standard error & Standard deviation \\
\hline $2 \times 10^{-6}$ & $3 \times 10^{-6}$ & 0.9782 & $1.33 \times 10^{-7}$ & $2.66 \times 10^{-7}$
\end{tabular}

\section{Conclusions}

The GN-PTA-Nafion was successfully prepared and characterized. SEM results showed that the particle size remained its crystallinity after the milling, whereas XRD identified the particle size of milled graphite were all smaller than $100 \mathrm{~nm}$ with the peak at around $26^{\circ}$. The milling for a period of 10 hours with a speed of $250 \mathrm{rpm}$ has resulted in the smallest particle size in the study, which is $11.75902 \mathrm{~nm}$. The method of polishing the GCE using alumina slurry was proven to be effective and increased the sensitivity of the detection. The GN-PTA-Nafion had great sensitivity and faster electron transfer compared to the bare GCE, GN modified GCE, and PTA modified GCE. The most suitable concentration of GN $(0.2$ mol L ${ }^{-1}$ ) for loading on GCE surface modification was used. The scan rate of $100 \mathrm{mV} \mathrm{s}^{-1}, \mathrm{pH}$ 8 of supporting electrolyte, and equilibrium time of 5 seconds were the optimized conditions that were used for further measurements. The modified electrode showed a great reproducibility with a relative standard deviation of $2.51 \%$. The LOD and LOQ obtained were 0.3995 and $1.332 \mathrm{~mol} \mathrm{~L}^{-1}$, respectively.

\section{Funding}

This work was supported by the Ministry of Education, Malaysia, through Fundamental Research Grant Scheme FRGS/1/2017/WAB09/UMT/02/4 (FRGS Vote 59487) as well as the Central Laboratory and Faculty of Science and Marine Environment, Universiti Malaysia Terengganu for providing laboratory facilities and instrumentation.

\section{Acknowledgments}

This paper has no acknowledgment. 


\section{Conflicts of Interest}

\section{The authors declare no conflict of interest.}

\section{References}

1. Abo, R.; Kummer, N.A.; Merkel, B.J. Optimized photodegradation of bisphenol A in water using $\mathrm{ZnO}, \mathrm{TiO}_{2}$ and $\mathrm{SnO}_{2}$ photocatalysts under UV radiation as a decontamination procedure. Drinking Water Engineering and Science 2016, 9, 27-35, https://doi.org/10.5194/dwes-9-27-2016.

2. Corrales, J.; Kristofco, L.A.; Baylor Steele, W.; Yates, B.S.; Breed, C.S.; Spencer Williams, E.; Brooks, B.W. Global assessment of bisphenol a in the environment: Review and analysis of its occurrence and bioaccumulation. Dose- Response 2015, 13, 1-29, https://doi.org/10.1177/1559325815598308.

3. Deng, P.; Xu, Z.; Kuang, Y. Electrochemical determination of bisphenol A in plastic bottled drinking water and canned beverages using a molecularly imprinted chitosan-graphene composite film modified electrode. Food Chemistry 2014, 157, 490-497, https://doi.org/10.1016/j.foodchem.2014.02.074.

4. Wu, C.; Cheng, Q.; Li, L.; Chen, J.; Wu, K. Synergetic signal amplification of graphene-Fe $\mathrm{O}_{3}$ hybrid and hexadecyltrimethylammonium bromide as an ultrasensitive detection platform for bisphenol A. Electrochimica Acta 2014, 115, 434-439, https://doi.org/10.1016/j.electacta.2013.10.188.

5. Li, C.; Zhou, Y.; Zhu, X.; Ye, B.; Xu, M. Construction of a sensitive bisphenol A electrochemical sensor based on metal-organic framework/graphene composites. Int. J. Electrochem. Science 2018, 13, 4855-4867, https://doi.org/10.20964/2018.05.52.

6. Vieceli, N.C.; Gonzatti, C.F.; Marzotto, J.A.; Filho, I.N. Influence of the solvent polarity and ph over the extraction of bisphenol a from samples of sanitary landfill leachate. WIT Transactions on Ecology and the Environment 2011, 148, 65-72, https://doi.org/10.2495/RAV110071.

7. Arar, S.; Alawi, M. A new solvent extraction method with gas chromatography-mass spectrometry for bisphenol A determination in canned foods. Acta Chromatographica 2017, 31, 1-8, https://doi.org/10.1556/1326.2017.00388.

8. Aristiawan, Y.; Aryana, N.; Putri, D.; Styarini, D. Analytical method development for bisphenol A in tuna by using high performance liquid chromatography-UV. Procedia Chemistry 2015, 16, 202-208, https://doi.org/10.1016/j.proche.2015.12.042.

9. Li, K.H.; Zhu, L.X.; Liu, R.R.; Meng, W. Determination of bisphenol A in beer by immunoaffinity column tandem high-performance liquid chromatography. Advances in Computer Science Research 2015, 230-234, https://doi.org/10.2991/icitmi-15.2015.40.

10. Peng, X.; Kang, L.; Pang, F.; Li, H.; Luo, R.; Luo, X.; Sun, F. A signal-enhanced lateral flow strip biosensor for ultrasensitive and on-site detection of bisphenol A. Food and Agricultural Immunology 2018, 29, 1-12, https://doi.org/10.1080/09540105.2017.1365822.

11. Cammarota, M.; Lepore, M.; Portaccio, M.; Di Tuoro, D.; Arduini, F.; Moscone, D.; Mita, D.G. Laccase biosensor based on screen-printed electrode modified withthionine-carbon black nanocomposite, for Bisphenol A detection. Electrochimica Acta 2013, 109, 340-347, https://doi.org/10.1016/j.electacta.2013.07.129.

12. Wu, L.; Deng, D.; Jin, J.; Lu, X.; Chen, J. Nanographene-based tyrosinase biosensor for rapid detection of bisphenol A. Biosensors and Bioelectronics 2012, 35, 193-199, https://doi.org/10.1016/j.bios.2012.02.045.

13. Huang, X.; Huang, D.; Chen, J.Y.; Ye, R.; Lin, Q.; Chen, S. Fabrication of novel electrochemical sensor based on bimetallic Ce-Ni-MOF for sensitive detection of bisphenol A. Analytical and Bioanalytical Chemistry 2020, 412, 849-860, https://doi.org/10.1007/s00216-019-02282-3.

14. Shi, R.; Liang, J.; Zhao, Z.; Liu, A.; Tian, Y. An electrochemical bisphenol A sensor based on one step electrochemical reduction of cuprous oxide wrapped graphene oxide nanoparticles modified electrode. Talanta 2017, 169, 37-43, https://doi.org/10.1016/j.talanta.2017.03.042.

15. Wang, M.; Shi, Y.; Zhang, Y.; Wang, Y.; Huang, H.; Zhang, J.; Song, J. Sensitive electrochemical detection of bisphenol A using molybdenum disulfide/Au nanorod composites modified glassy carbon electrode. Electroanalysis 2017, 29, 2620-2627, https://doi.org/10.1002/elan.201700411.

16. Jurek, A.; Leitner, E. Analytical determination of bisphenol A (BPA) and bisphenol analogues in paper products by GC-MS/MS. Food Additives and Contaminants - Part A Chemistry, Analysis, Control, Exposure and Risk Assessment 2017, 34, 1225-1238, https://doi.org/10.1080/19440049.2017.1319076.

17. Rigopoulos, A.; Samanidou, V.; Touraki, M. Development and validation of an HPLC-DAD method for the simultaneous extraction and quantification of bisphenol-A, 4-hydroxybenzoic acid, 4-hydroxyacetophenone and hydroquinone in bacterial cultures of lactococcus lactis. Separations 2018, 5, https://doi.org/10.3390/separations5010012.

18. Jusoh, N.S.; Azmi, A.A.; Ahmad, A. Enzyme-linked immunosorbent assay (ELISA)-based-sensor for determination of benzo[a]pyrene in river water using screen-printed gold electrode. Malaysian Journal of Analytical Sciences 2017, 21, 518-526. https://doi.org/10.17576/mjas-2017-2103-01.

19. Jusoh, N.S.; Omar, T.F.T.; Ahmad, A. Thiol modified amperometric immunosensor for benzo[a]pyrene detection in surface river water samples. Malaysian Journal of Analytical Sciences 2019, 23, 849-860. 
20. Devi, K.S.S.; Syasya, M.; Krishnan, U.M. Emerging vistas on electrochemical detection of diabetic retinopathy biomarkers. Trends in Analytical Chemistry 2020, 125, 1-13, https://doi.org/10.1016/j.trac.2020.115838.

21. Shim, K.; Kim, J.; Shahabuddin, M.; Yamauchi, Y.; Hossain, M.S.A.; Kim, J.H. Efficient wide range electrochemical bisphenol-A sensor by self-supported dendritic platinum nanoparticles on screen-printed carbon electrode. Sensors and Actuators, B: Chemical 2018, 255, 2800-2808, https://doi.org/10.1016/j.snb.2017.09.096.

22. Koyun, O.; Gorduk, S.; Getchen, M.; Sahin, Y. A novel copper (11) phthalocyanine-modified multiwalled carbon nanotube-based electrode for sensitive electrochemical detection of bisphenol A. New Joural of Chemistry 2019, 43, 85-92, https://doi.org/10.1039/C8NJ03721C.

23. Shi, R.; Liang, J.; Zhao, Z.; Liu, Y.; Liu, A. In situ determination of bisphenol A in beverage using a molybdenum selenide/reduced graphene oxide nanoparticle composite modified glassy carbon electrode. Sensors 2018, 18, 1660-1669. https://doi.org/10.3390/s18051660.

24. Su, B.; Shao, H.; Li, N.; Chen, X.; Cai, Z.; Chen, X. A sensitive bisphenol A voltammetric sensor relying on AuPd nanoparticles/graphene composites modified glassy carbon electrode. Talanta 2017, 166, 126-132, https://doi.org/10.1016/j.talanta.2017.01.049.

25. Zhang, J.; Xu, X.; Chen, L. An ultrasensitive electrochemical bisphenol A sensor based on hierarchical Cemetal-organic framework modified with cetyltrimethylammonium bromide. Sensors and Actuators, B: Chemical 2018, 261, 425-433. https://doi.org/10.1016/j.snb.2018.01.170.

26. Huang, N.; Liu, M.; Li, H.; Zhang, Y.; Yao, S. Synergetic signal amplification based on electrochemical reduced graphene oxide-ferrocene derivative hybrid and gold nanoparticles as an ultra-sensitive detection platform for bisphenol A. Analytica Chimica Acta 2015, 853, 249-257, https://doi.org/10.1016/j.aca.2014.10.016.

27. Peng, J.; Feng, Y.; Han, X.X.; Gao, Z.N. Simultaneous determination of bisphenol A and hydroquinone using a poly(melamine) coated graphene doped carbon paste electrode. Microchimica Acta 2016, 183, 22892296, https://doi.org/10.1007/s00604-016-1865-9.

28. Dong, X.; Qi, X.; Liu, N.; Yang, Y.; Piao, Y. Direct electrochemical detection of bisphenol a using a highly conductive graphite nanoparticle film electrode. Sensors 2017, 17, 836-845, https://doi.org/10.3390/s17040836.

29. Garcia-Gonzalez, R.; Fernandez-Abedul, M.T.; Costa-Garzia, A. Nafion ${ }^{\circledR}$ modified-screen printed gold electrodes and their carbon nanostructuration for electrochemical sensors applications. Talanta 2013, 107, 376-381, https://doi.org/10.1016/j.talanta.2013.01.034.

30. Wan, J.; Si, Y.; Li, C.; Zhang, K. Bisphenol A electrochemical sensor based on multi-walled carbon nanotubes/polythiophene/Pt nanocomposites modified electrode. Analytical Methods 2016, 8, 3333-3338, https://doi.org/10.1039/C6AY00850J.

31. Panjiar, H.; Gakkhar, R.P.; Daniel, B.S.S. Strain-free graphite nanoparticle synthesis by mechanical milling. Powder Technology 2015, 275, 25-29, https://doi.org/10.1016/j.powtec.2015.01.056.

32. Motozuka, S.; Tagaya, M.; Ogawa, N.; Fukui, K.; Nishikawa, M.; Shiba, K. Effective preparation of graphite nanoparticles using mechanochemical solid-state reactions. Solid State Communications 2014, 190, 28-32, https://doi.org/10.1016/j.ssc.2014.03.023.

33. Krishna, B.G.; Rao, M.J. Chemical synthesis of graphite nanoparticles and study of microwave radiation absorption by graphite nanocomposites. International Journal of Advanced Research 2015, 3, 391-397.

34. Frag, E.Y.; Abdel-Hameed. R.M. Preparation, characterization and electrochemical application of CuNiO nanoparticles supported on graphite for potentiometric determination ofcopper ions in spiked water sample. Microchemical Journal 2019, 144, 110-116, https://doi.org/10.1016/j.microc.2018.08.060.

35. Zhou, Y.C.; Rahaman, M.N. Hydrothermal synthesis and sintering of ultrafine $\mathrm{CeO}_{2}$ powders. Journal of Materials Research 1993, 8, 1680-1686, https://doi.org/10.1557/JMR.1993.1680.

36. Tan, X.; Jaka, S.; Yang, W.; Tin, Y. Ball milling: a green mechanochemical approach for synthesis of nitrogen doped carbon nanoparticles. Nanoscale 2013, 5, 7970-7976, https://doi.org/10.1039/C3NR02328A.

37. Zhu, H.; Li, Y.; Song, Y.; Zhao, G.; Wu, W.; Zhou, S.; Xiao, W. Effects of cyclic voltammetric scan rates, scan time, temperatures and carbon addition on sulphation of $\mathrm{Pb}$ disc electrodes in aqueous $\mathrm{H}_{2} \mathrm{SO}_{4}$. Materials Technology 2016, 35, 135-140, https://doi.org/10.1080/10667857.2015.1133157.

38. Huang, W. Voltammetric determination of bisphenol A using a carbon paste electrode based on the enhancement effect of cetyltrimethylammonium bromide. Bulletin Korean Chemical Society 2005, 26, 1560-1564, https://doi.org/10.5012/bkcs.2005.26.10.1560. 